\title{
The reform orientation of Higher Accounting Education in the information era
}

\author{
Zhimin Peng \\ Department of Accounting, Shanxi vocational college of finance and economics, Xianyang, 712000, \\ China
}

\begin{abstract}
Keywords: informatization; higher accounting education; influence; reform and innovation
Abstract. Nowadays, the application of information technology accelerates the development of economic globalization. The competition between countries and countries, enterprises and enterprises is becoming more and more intense. Informationization has become the lifeblood and core competitiveness in an enterprise and even a country. Informatization is making fundamental changes in social structure and economic distribution, and all countries in the world are paying close attention to the opportunities and challenges brought by informatization. Higher accounting education is an important part of higher education, which plays an important role in the popularization of higher education and the construction of lifelong education system. With the rapid development of information technology, informationization creates a more innovative educational environment into the higher accounting education, but also brings new problems.

This paper analyzes the opportunities and challenges faced by higher accounting education under the informationization influence, and put forward some strategies.
\end{abstract}

\section{Introduction}

In the environment of network informatization, the informationization of accounting work has got a lot of development opportunities. The network information technologyprovides strong support for theaccounting education, which greatly improves the level of accounting education and complies with the times development demand of network informationization. However,this also brings more new challenges and conflicts with the pattern of the traditional education system. Facing the historical opportunity of information technology, the higher accounting education should advance with the times, improve innovation, self-improvement and evolution to ensure the smooth and healthy development.

\section{The impact of the development of information technology on higher accounting education}

The rapid development of information technology expands market of the higher accounting education. Since the beginning of the new century, the trade globalization, economic integration and informationization have become the most distinctive features of the world's development. The environment of China's economic society has changed with the interaction with the world, such as rapid development in economic, industrial structure adjustment and continuous extension of the industrial chain, and the maintenance of independent innovation capacity and independent intellectual property rights are getting more and more attention. These changes have forced the China's industrial structure to make a deep adjustment. Innovation capacity becomes the most important elements of economic development.At present, the informationization is one of the most powerful engines for economic development, which has been recognized by Chinese and foreign scholars. The innovation ability, high efficiency and high utilization rate brought by informatization are the guarantee for the continuous development of an enterprise, an industry, an area and even a national economy. Therefore, the construction and application of information based on the Internet-the reinforcing application of a significant feature as the new round of information technology climax - to reduce transaction costs, promote technological innovation, and enhance the quality of elements into the world economic integration have been surging rise. 
In the wave of information technology, the change of economic growth pattern and social basic framework, the increase of mobility of labor forcecross-industry, people has more and more demands on their lifelong learning and on-the-job learning. In addition, the increase of foreign-funded enterprises and foreign staff will increase the requirements in vocational education, financial English and computer knowledge.These factors will inevitably increase the demand for senior management personnel to promote the development of higher accounting education and further expand the market inhigher accounting education.

The information technology revolution breaks the traditional pattern of higher accounting education. Information technology revolution refers to the large-scale development, infiltration, expansion and utilization of information technology as its basic content of social information activities. This technological revolution greatly enhanced the ability of human for processing and using information, and it has become one of the most active factors in a national and social development. With the development of information technology, people gradually realized that information knowledge is more important and valuablethan material products. The production, circulation and consumption of information itself are the most important social and economic activities in the current society. Information technology has become the dominant technology, information industry has become the leading industry, and information has become the theme of this era.

Accounting as an indispensable part of economic life under the information society and the new economic era background, the information technology will be greatly used in the management.The shift of development of information processing in accounting area from the traditional hand-processing to computerization is the major change in the accounting operation technology and information processing strategy, which proposes a series of new issues on accounting ideas and theory, and gradually break the traditional accounting pattern, and establish a new accounting theory. These will have a profound impact on higher accounting education.

\section{The information brought unprecedented development opportunities}

Chinese higher accounting education will gradually open to the market, community and the world with the construction and development of information technology. This change will bring unprecedented development opportunities for Chinesehigher accounting education.

Informatization has brought us advanced accounting education ideas and concepts from developed countries. With the development and popularizationof information technology, especially via thenetwork communication technology to widely use the remote communication in various levels around the world has a very important significance for us to deeply understand the international advanced educational philosophy, school system and personnel training mode, meanwhile, based on the reality of our higher accounting education, it is important to select the essence, abandon its dross, to reform the current educational system and regulations, to optimize teaching contents and teaching methods, to improve the quality, efficiency and efficiency of education, to establish the education purpose of "service-aiming and job-orientation", to improve the quality of personnel, improve the quality of education, and improve the quality of talent training.

Information provides higher accounting education with technical support. Thegoal of "building a higher popular accounting education and the learning-oriented society" gradually becomes possible under the information age and the global Internet under the unified platform. Because of the characteristics of network communication, such as fast speed and wide coverage, it provides people in different areas with various information exchanges. It also makes the higher accounting education have the characteristics of timely dissemination and extensive study, and provides the accounting education withefficient technical support.For example, the application of distance education technology breaks the limitation of time and space, and one can access to knowledge in any terminal equipment. You do not have to follow the traditional way of fixed-point learning, and be able to accept higher financial education without leaving home. 
The development of network benefits for promoting the innovation ability of vocational college students. The extensive network information resources and more convenient mode of international exchange brought byinformatization can ensure students to acquire more perfect knowledge, study the research results of experts and scholars from all over the world, and provide sufficient nutrients for students' practical learning.

\section{The severe challenges of higher accounting education}

Challenges to students' thinking. Under the background of network informatization, the way of accepting various cultural ideas is more convenient, extensive and varied, and the educational ideas, ways and methods, and cultural thoughts among countries are further collided. The difference of professional background and culture might lead to confusion for while receiving education. How to solve the issues generated from different educational ideas is a test and challenge for the Chinese accounting education.

Challenges to the traditional educational model.In the era of informationization, the special requirements are put forward for the cultivation of higher accounting talents: First, in order to conform to the development trend of global informationization, economic integration and globalization, higher accounting talents in China must master the international common language in order to cooperate with the international advanced accounting Industry, and become an international talent. Second, the popularity of information technology requires us to master a variety of network operating skills. Third, in the information society and the new economy era, the creative thinking, innovative thinking and personal potential of higher accounting talents are more and more wanted, which have become the top priority of modern education. However, we should clearly realize that the improvement of talent quality must be achieved through education. The Chinese current education model cannot adapt to the development of information technology, so we must change the traditional mode of education, from the examination-oriented education gradually developed into quality education.

Challenge to the quality concept of accounting education.China's traditional view of the quality of education is based on the number and depth of knowledge as the main target, or even the only standard. But with the advent of the information age, this traditional view of the quality of education has been unable to meet the requirements of the times, how to culture the students to adapt to information technology, to survive and developin the new economic era, and to demonstrate their talent will become the new educational quality standards. Professor Lu Jie, a modern educator, said: "This kind of talent can not only take the initiative to grasp the various symbols in the network, but also be able to conduct symbolic communication and creation, thus becoming the mainbody of the network era, while no becomingsubjectivity of computer slaves ", whose opinion is very representative and practical answer.

Challenges to the traditional teaching system. Computer interconnection and information sharing as one of the signs of the rapid development of computer and information processing technologies, it was built via Internet and was greatly shorten the time and space, resulting in the rapid adjustment of the social structure of the industry and the changing job positions. At the same time, higher vocational education is required to cultivate talents with international conception, global consciousness, competition consciousness and innovative idea. Higher accounting education is the first line of production, management and output of higher accounting talents. With the lag of traditional teaching contents and teaching system, the quality of modern higher accounting talents in the information age has been unable to meet the existing teaching system.

\section{Coping strategies}

In the new era of network information, higher accounting education must abandon the old teaching philosophy and thinking in traditional education, and should keep up with the pace of the times, keep pace with the times, and deepen the reform and innovation. It is required to explore the teaching 
objectives, teaching content, teaching methods and other aspects to find out the coping strategy to ensure that the personnel training can meet the needs of talent quality of contemporary society.

Goal of reform and innovation. What kind of senior accounting talents thehigher accounting education wants to cultivate? The result of this problem has been given a clear answer under the new information technology. The modern senior accounting talents not only have the senior accounting ability, more importantly, they should have the logical thinking ability, learning innovation ability, and creativity. The former was often considered as the main training goal in traditional accounting education or even the only goal,and the latter was easy to be ignored, resulting in the disconnection between talent and society. Therefore, in today's society, the goal of the higher accounting education in the information age should be changed to: cultivate the senior accounting ability, focus on the students' innovation ability, and enable them to have the innovation ability.

Content of reform and innovation.In the rapidly changing information age, with the social and economic development, the trend of specification of industry is clear, which requires a wide variety of senior accounting talents. Therefore, adhering to diversified teaching is the necessary means for higher accounting education to adapt to the market economy and rapid social changes - diversified professional curriculum system, diversified teaching content, diversified accounting theory and diversified personnel training methods.

Reform and innovation ofteaching methods. In the information age, the traditional accounting teaching mode based on the knowledge transmission and "duck-stuffing" type of teaching has become increasingly outdated. The modern higher accounting teaching method should rely on the technical support provided by the information application technology, enrich and improve the teaching method creatively. First, open teaching was adopted, relying on multimedia and network information technology, and timely update teaching theory to establish a reasonable professional knowledge base, to expand the knowledge of students, and to improve teaching efficiency; Second, "heuristic" teaching method was used to guide students to explore scientific thinking and innovation, combine the learning and practice, and learn for their own use. It is important to make them understand what expertiseknowledge is, but also let them know why and how to use it, so as to enable them to make knowledge become their own thing, continue to deepen understanding, and truly improve the quality and ability of students themselves; Third, to improve the content of the examination, increase thetest questions of comprehensive analysis and the problem-solving abilities, gradually reduce the content of rote memorization, reasonable evidence can be scored to encourage students to have their own analytical problems.

Reform and innovation of education investment mode. Deepen the reform of higher accounting education innovation, the increase in curriculum, teaching materials reform, teaching conditionsimprovement, and teacher training should be considered. All of these need to be invested. However, the current status of higher accounting education is: the depletion of educational resources seriously hinders the sustainable development of higher accounting education. Therefore, the sources of higher accounting education cannot rely solely on the government and the school supplies, but should play the advantages of resource aggregation,exploit potentialities, and explore market-oriented and industrial-oriented method of running schools and make full use of social resources to attract capital financing. Only in this way can we guarantee the smooth progress of the reform and development of higher accounting education and ensure the sustainable development of higher accounting education in China under the informationization.

\section{Conclusion}

In conclusion, the development of network information brings great opportunitiesto the higher accounting education, while along with challenges. Traditional education patterns and situation in the current social and economic development has highlighted the lag and obsolete.How to carry out reform and innovation, ensure thehigher accounting education with the times, make sure its escalation and optimization with the tide of information technology, and culture senior accounting 
talents that meet the information-based society, and train senior accounting talents with creativity are the vital questions needing to resolve.

\section{References}

[1] Dai HY. The Reform of Accounting Major in Secondary Vocational Education.New Course of Study 2012,07:63.

[2]Ge C. The Influence of Network Informatization on Accounting Education. China Education Innovation Herald 2013,22:155.

[3]Pei YF. The Present Situation and Countermeasure of Accounting Teaching in Secondary. Examination Weekly 2014,99:172.

[4] $\mathrm{Fu} \mathrm{YL.} \mathrm{Financial} \mathrm{Monitoring} \mathrm{under} \mathrm{Informatization.} \mathrm{Beijing:} \mathrm{Chinese} \mathrm{Financial} \mathrm{and}$ economicalpress; 2003.

[5]Yang H.Teaching Reform and Innovation of Higher Vocational Accounting Education. China Adult Education; 2006,(11).

[6]Chen Y. The Modernization and Informatization of Higher Education. Research for Vocational Technology Education 2006,(8).

[7]Wang YB. Higher education popularization, internationalization, networking and legalization. Kunming: Yunnan University Press. 2002. 